\title{
A INSCRIÇÃO \\ DO SUJEITO \\ NA ESCRITA ACADÊMICA \\ NUMA

\author{
PERSPECTIVA \\ DIALÓGICA
}

\section{LA INSCRIPCIÓN DEL SUJETO EN LA ESCRITURA ACADÉMICA EN PERSPECTIVA DIALÓGICA}

\author{
THE INSCRIPTION OF THE SUBJECT IN ACADEMIC WRITING UNDER A DIALOGIC \\ PERSPECTIVE
}

\author{
Sandro Braga* \\ Rodrigo Acosta Pereira** \\ Universidade Federal de Santa Catarina
}

\begin{abstract}
RESUMO: Na esfera acadêmica é comum encontrarmos textos que não reverberam especificidades enunciativo-discursivas de seu contexto de produção e de circulação. Tal dissonância é fruto, em geral, do desconhecimento dos alunos em torno do funcionamento dos gêneros discursivos acadêmicos. A fim de contribuir para amenizar esse hiato, este trabalho busca compreender os modos como o sujeito na posição de aluno-universitário é acometido em sua escrita nessa esfera de atividade humana. Para isso, aliando pressupostos teóricos da Linguística Aplicada e da Análise do Discurso, analisa-se a produção textual decorrente da uma atividade avaliativa desenvolvida por um estudante no final do primeiro semestre de seu ingresso na Universidade. O critério de seleção desse corpus deu-se em virtude de que esse aluno apresentou um maior grau de dificuldade - em relação aos demais colegas - para as produções escritas no âmbito dos gêneros acadêmicos no decorrer da disciplina de Leitura e Produção Textual Acadêmica oferecida no curso de graduação. A análise apontou uma reflexão de como é possível, por meio de uma relação dialógica, nos termos bakhtinianos, entre professor e aluno, mobilizar o sujeito-aluno que escreve nessa esfera para que, ao escrever, possa também se inscrever.
\end{abstract}

PALAVRAS-CHAVE: Leitura. Produção textual. Gênero do discurso acadêmico.

RESUMEN: En el ámbito académico es común encontrar textos que no reverberan especificidades enunciativa-discursivas de su contexto de producción y circulación. Esta inconsistencia es el resultado, en general, de la falta de conocimiento de los estudiantes

\footnotetext{
*Professor no Programa de Pós-graduaçãoem Linguística. E-mail: sandrocombraga@gmail.com.

** Professor no Programa de Pós-graduação em Linguística e no Programa de Mestrado Profissional em Letras (PROFLETRAS). E-mail: drigo_acosta@yahoo.com.br
} 
del funcionamiento de los géneros académicos. Para ayudar a aliviar esta brecha, este trabajo busca entender las formas en que el sujeto en la posición de estudiante universitario se ve afectado en su escritura. Para ello, la combinación de los supuestos teóricos de Lingüística Aplicada y Análisis del Discurso, analiza la producción textual como resultado de una actividad evaluativa desarrollada por un estudiante el final del primero semestre de su ingreso a la Universidad. Los criterios de selección de este corpus se dieron por causa de este estudiante mostró un mayor grado de dificultad - en relación con otros colegas - para las producciones escritas en los géneros académicos en el curso de lectura y producción de textos académicos que ofrece el curso graduación. El análisis indicó un reflejo de cómo es posible a través de una relación dialógica, en términos de Bakhtin, entre profesor y alumno, movilizar el estudiante sujeto que escribe este ámbito por lo que la escritura también puede suscribirse.

PALABRAS CLAVE: Lectura. Producción textual. Género de discurso académico.

ABSTRACT: In the academic sphere, it is common that one find texts which do not reflect the enunciative-discoursive specificities of their context of production and circulation. This inconsistency is a result, in general, of the students' lack/misunderstanding concerning the academic discourse genres. In order to contribute to decrease this gap, this paper aims at understanding the manners how the subject in a position of university student is stricken in his/her writing productions in the academic sphere. To do so, we ally theoretical assumptions from Applied Linguistics and Discourse Analysis to analyze the text production as a result of an evaluative activity developed by a student in the end of the first term of his entrance in the university. The criterion used for choosing the corpus for analysis was the degree of difficulty faced by this student, when compared to his classmates, in the production of texts under the perspective of academic discourse genres in the Reading and Text Production discipline offered in a undergraduate course. The analysis demonstrated a reflection of how it is possible through a dialogic relationship, in Bakhtin's Circle terms, to mobilize the student (as a subject) who writes in this academic sphere in order to be inscribed in it as well.

KEYWORDS: Reading. Text production. Academic discourse genre.

\section{INTRODUÇÃO}

Os estudos de letramento vêm mostrando que a compreensão e a produção de textos sob a arquitetônica dos diversos gêneros discursivos, tanto escritos quanto orais (como de outra forma semiótica), requerem conhecimentos que extrapolam a mera (de)codificação. Os contextos sociais de produção e circulação dos gêneros do discurso e, por conseguinte, seus potenciais interlocutores, por exemplo, engendram-se na construção de sentido de toda e qualquer produção textual. Nesses termos, (re)conhecer a complexa dinâmica das diferentes esferas da atividade humana torna-se fundamental para que as produções textuais atinjam seus objetivos.

Na esfera acadêmica, entretanto, na qual predomina a circulação de gêneros discursivos complexos (BAKHTIN, 1997 [1979]), é comum encontrarmos textos que não reverberam especificidades enunciativo-discursivas de seu contexto de produção e de circulação (que, em termos gerais, é a universidade). Tal dissonância é fruto, em geral, do desconhecimento dos alunos em torno do funcionamento dos gêneros discursivos acadêmicos. Assim, a fim de contribuir para amenizar o hiato existente entre os níveis de compreensão exigidos pelos professores e os níveis de compreensão que os alunos, de fato, possuem, faz-se importante pesquisar e implementar ações que busquem compreender os modos como o sujeito na posição de aluno-universitário é acometido em sua escrita nessa esfera de atividade humana.

Aliando pressupostos teóricos da Linguística Aplicada e da Análise do Discurso, analisa-se a produção textual decorrente da última atividade avaliativa desenvolvida por um estudante no final do primeiro semestre de seu ingresso na Universidade. O critério de seleção desse corpus deu-se em virtude de que esse aluno apresentou um maior grau de dificuldade - em relação aos demais colegas - para as produções escritas no âmbito dos gêneros acadêmicos no decorrer da disciplina de Leitura e Produção Textual Acadêmica oferecida no curso de graduação em Letras - Português, no semestre 2015-1.

Salienta-se que, no decorrer do semestre, buscou-se diversificar os elementos envolvidos nas práticas de leitura e de escrita por entendê-las como emergentes de processos dialógicos, na concepção bakhtiniana (BAKHTIN, 1997 [1979]; MEDVIÉDEV, 2012 [1928]; VOLOCHÍNOV, 2013 [1930]). Portanto, nas produções textuais e atividades leitoras, procurou-se despertar a atenção dos 
alunos para os potenciais interlocutores dos textos em questão, os objetivos almejados com o projeto de dizer de cada texto e os seus contextos de produção e de circulação. Além disso, intentou-se evidenciar os aspectos discursivos e ideológicos que permeiam, inevitavelmente, todos os textos, procurando-se, dessa forma, fomentar um exercício crítico, cuidadoso e menos ingênuo em relação às leituras realizadas e também às produções escritas para, desse modo, despertar o aluno para o fato de que a escrita e a leitura devem ser vistas, também, como tomadas de posição (responsivas e ideológico-valorativas) diante daquilo que é dito.

Por entender que, por diversos fatores, o espaço da sala de aula, em contexto universitário, por vezes, não produz reflexão em relação às produções textuais dos alunos e, também, por perceber a heterogeneidade desses sujeitos, bem como de suas necessidades em torno da compreensão acerca da constituição e do funcionamento dos gêneros acadêmicos, investiu-se no rompimento dessa práxis, buscando, num processo dialógico, dar retornos individuais aos estudantes acerca de suas produções, além de propor diferentes estratégias de leitura e de escrita. Desse modo, investiu-se de forma ostensiva na escrita e reescrita dos textos, a fim de se mostrar que todo texto é sempre passível de tornar-se outro, dada a sua condição de relativo acabamento (BAKHTIN, 1997 [1979]); ou nos termos de Orlandi (2001, 2007 [1990]), o texto do ponto de vista empírico apresenta começo, meio e fim, mas considerado como discurso, é sempre da ordem da incompletude.

Assim, a leitura e a produção textual pensadas a partir das concepções de letramento numa perspectiva dialógica implicam compreendermos essas atividades como ações discursivas nas diversas esferas de atividade humana, ou seja, relacionadas diretamente à vida e aos sujeitos em relações de interlocução, para, desse modo, instigar o aluno, ao ler e escrever, inscrever-se como sujeito, seja frente ao texto que lê e interpreta, seja frente ao texto que escreve.

Diante desse contexto, este trabalho intenta analisar os modos de produzir sentido ao ato ler e à produção de escrita no âmbito do letramento acadêmico. Interessa-nos interrogar, também sob a perspectiva discursiva, como o sujeito na Universidade é arregimentado no bojo de sua produção de modo a inscrever-se em seu projeto de dizer, uma vez que está constantemente submetido aos já ditos (BAKHTIN, 1998 [1975]) das formulações desse lugar de produção de conhecimento. Além disso, busca-se atentar para o modo como os aspectos ideológico-valorativos, que permeiam toda e qualquer enunciação, são constitutivos das práticas discursivas, inclusive, ou sobretudo, quando o sujeito se assume na posição de aluno universitário.

\section{OS ESTUDOS DO LETRAMENTO}

De início, o termo letramento chega às escolas como forma de diretrizes curriculares e pedagógicas, sendo utilizado na fundamentação das práticas de alfabetização em sala de aula. No entanto, mais recentemente, a compreensão de letramento tem sido alçada às práticas sócio-histórico-culturais de leitura e de escrita, visando à inserção do sujeito em práticas sociais múltiplas e diversificadas. Nesse sentido, o fenômeno do letramento é considerado sempre socialmente situado e consociado a aspectos socioeconômicos, históricos, culturais, políticos e educacionais.

Considerando tais abordagens, Street (1995) compreende que o letramento pode ser visto sob duas perspectivas: 1) a do modelo ideológico - que concebe o letramento como um conjunto de práticas sociais situadas envolvendo a leitura e a escrita; 2) a do modelo autônomo - que parte da premissa de que o ato de ler é uma mera atividade de decodificação de palavras, referindo-se, basicamente, às habilidades individuais do sujeito.

Aqui, nos endereçamos numa abordagem ideológica e, portanto, sociocultural, ou seja, consideramos as práticas sociais de uso da leitura e da escrita sob o matiz das situações interacionais. A essa perspectiva, alinhamos, ainda, a do discurso, que concebe essas práticas decorrentes das condições de produção e, por conseguinte, compreendem fundamentalmente o sujeito e a situação historicamente implicados.

Na perspectiva sociocultural, o conceito de letramento encontra lugar nos Novos Estudos do Letramento (STREET, 1984, 1995; BARTON, 1994; BARTON; HAMILTON, 1998; GEE, 1999, 2001; LEA; STREET, 2006), que consideram o letramento crítico, no sentido de dar ênfase aos aspectos ideológicos da prática social. Com base na visão ideológica, Street propõe o termo letramentos, 
no plural, pois, assim, abarcaria a ideia de letramentos múltiplos a que o sujeito fica exposto no seu contexto social. A caracterização novos a esses estudos deve-se à concepção de que leitura, escrita e sentido são sempre situados em práticas sociais específicas. Esses estudos privilegiam os sentidos nos processos socioculturais e as habilidades técnicas/individuais dos sujeitos envolvidos em práticas letradas.

Dessa forma, as práticas de letramento são compreendidas como práticas culturais discursivas, que determinam a produção e a interpretação de textos em contextos específicos. Ou seja, as práticas de letramento são dependentes dos contextos de uso, assim constituídas ideologicamente e, por isso, não podem ser tratadas como técnicas e/ou neutras.

Por isso, é fundamental, na questão do letramento, a promoção dos chamados eventos de letramento, sendo considerados como qualquer situação em que a escrita é parte integrante da natureza das interações entre os participantes e de seus processos de interpretação. Sinteticamente pode ser entendido como qualquer atividade que envolva a palavra escrita.

Considerando-se na perspectiva social da escrita uma situação comunicativa com atividades que usam ou pressupõem o uso da língua escrita, um evento de letramento não se diferencia de outras situações da vida social, pois envolve uma atividade coletiva em que os vários participantes mobilizam coletivamente diferentes saberes segundo interesses individuais e comuns.

Em virtude disso, Street (1995) concebe os letramentos como múltiplos, sujeitos às relações de poder, em que as pessoas realizam novos letramentos a todo o momento, variando de uma comunidade para outra, de acordo com as condiçoes socioculturais. Ao que Gee (1999) acrescenta, quanto mais o sujeito assume papéis distintos, melhor para desenvolver os seus "kits de identidade". Isso quer dizer que uma pessoa cumpre diferentes funções na sociedade e, em cada uma, faz determinado uso da linguagem, constituindo-se no âmbito de seus letramentos múltiplos.

\section{PRINCIPAIS ABORDAGENS SOBRE A ESCRITA NO ENSINO SUPERIOR}

O conceito de letramento acadêmico desenvolvido no âmbito dos Novos Estudos do Letramento entende que as práticas escritas não podem ser neutras ou desarticuladas dos contextos de uso.

De acordo com Lea e Street (1998), a escrita do estudante no Ensino Superior é compreendida a partir de três perspectivas: (i) modelo dos estudos das habilidades, que consiste num conjunto de habilidades individuais e cognitivas que os estudantes precisam adquirir e desenvolver para, assim, transferi-las para os contextos mais amplos da universidade; (ii) modelo da socialização acadêmica, que entende o professor como o principal responsável por introduzir os alunos na cultura universitária a fim de que eles assimilem os modos de falar, raciocinar, interpretar e usar as práticas de escrita valorizadas nas disciplinas e áreas temáticas da universidade; e (iii) modelo do letramento acadêmico, no qual os letramentos são vistos como práticas sociais e, portanto, constitutivos dos vários setores da esfera acadêmica; concentra-se nos significados que os sujeitos atribuem à escrita, partindo de questões epistemológicas que envolvem as relações de poder entre instituição, professores e alunos, além de investigar as identidades sociais e a história de letramento dos sujeitos, bem como o processo de aculturação pelo qual o aluno passa ao engajar-se em situações interativas típicas dessa esfera. Para os autores, esses três modelos não se excluem, mas são dependentes, pois o aluno precisa conhecer as convenções que regulam as práticas de letramento da universidade para se engajar nos modos de uso da escrita valorizados pelas disciplinas, áreas temáticas e diferentes situações comunicativas, sem, contudo, desconsiderar sua história prévia de letramento e seus valores identitários.

Nesse sentido, pensar o letramento acadêmico numa perspectiva discursiva é importante uma vez que, ao aprender as convenções que regulam um gênero do discurso, o estudante está, efetivamente, adentrando ao modo de funcionamento de novas práticas interlocutivas no interior de esferas sociais outras.

Na perspectiva de Lea e Street (1998), o estudante vê a necessidade de utilizar um repertório linguístico adequado a cada departamento, disciplina e áreas temáticas, como uma das principais características das práticas de letramento acadêmico. Ao tentar 
adequar seu discurso às práticas acadêmicas, o aluno procura aderir aos Discursos Dominantes legitimados pela universidade, o que não pressupõe o engajamento efetivo nessas práticas (GEE, 1999)'.

Nessa direção e tomando como base a concepção ideológica do letramento, entende-se que o Ensino Superior é formado por diversas práticas sociais, nas quais professores e alunos constituem-se a partir das posições sujeito que assumem ao estabelecer relações de interlocução nessa esfera enunciativa com a e pela escrita.

Partindo do pressuposto de que as pessoas têm e fazem uso de diferentes letramentos associados a diferentes contextos, o letramento acadêmico fica caracterizado por requerer formas diferenciadas para a escolarização, daí a importância de se fomentar, também, no ensino universitário, práticas de letramentos decorrentes de eventos específicos de letramento.

No caso do letramento acadêmico, o domínio social em destaque é o acadêmico, assim, as articulações dizem respeito ao uso de linguagens especializadas nesse contexto. E fazem referência aos papéis sociais (pelo menos desejáveis) de alunos e professores no que diz respeito às finalidades de os alunos estarem nesse domínio e às relações estabelecidas com o conhecimento e com o saber. Todos esses aspectos inter-relacionam-se, inevitavelmente, pois o letramento, compreendido como práticas sociais, envolve (GEE, 1999, 2001) formas de ser, falar, ouvir, escrever, ler, agir, interagir, acreditar, valorizar, sentir, usar recursos, ferramentas, tecnologias capazes de ativar identidades relevantes num dado contexto.

O letramento crítico, na visão de Gee (1999), representa um caminho para libertação e para emancipação, capaz de conceder aos sujeitos o poder de participar de letramentos dominantes, de questionar a realidade em torno de si, bem como de analisar práticas sociais da língua de maneira crítica, com apoio da metalinguagem que as constituem.

Considerando que o letramento representa maneiras sociais e culturais de se proceder através do uso de textos, essa visão compreende o letramento a partir das maneiras que os indivíduos, grupos, comunidades e sociedades colocam as práticas letradas em funcionamento. Isso implica estudar salas de aula como lugares sociais e culturais onde práticas particulares podem servir na ação de questionar quais textos, formas de falar, ler, escrever e comportar-se são privilegiados e por quê.

Desse modo, é importante que as propostas de trabalho de leitura e de escrita envolvam sempre textos de diferentes gêneros a fim de que os alunos possam não apenas aprender, mas apreender e aprimorar o uso da língua, sobretudo, aqueles constituídos pelo discurso acadêmico caracterizado pela mobilização do dizer científico.

É importante salientar que enquanto alguns letramentos são legitimados por instituições, outros são desvalorizados. Hamilton (2000) apresenta a noção de letramentos dominantes, relacionados às práticas de organizações formais, como as da escola, fazendo parte dos discursos especializados da comunidade educacional, padronizados e definidos de acordo com os efeitos formais da instituição ou com as disciplinas acadêmicas. Nessa noção, os professores controlam o acesso ao conhecimento, de acordo com as situações contextuais e objetivos educacionais. Deve-se considerar que as práticas escolares são muitas, sendo que, às vezes, a aprendizagem é separada do uso, distribuída em especialidades, o que pode gerar problemas para o ensino e para a aprendizagem.

\section{LETRAMENTO ACADÊMICO: POSSÍVEIS CONFLITOS E ALTERNATIVAS}

Retoma-se a ideia de que o letramento acadêmico requer formas especializadas, uma vez que emerge das práticas sociais mais escolarizadas. Assim, sendo a instância acadêmica um espaço de produção e sistematização do conhecimento, espera-se que circulem, em seu interior, textos cujas feições se diferenciem daquelas que circulam em outros níveis de escolarização e nos meios menos formais.

\footnotetext{
${ }^{1}$ Para Gee (1999), os "Discursos" não integram apenas aspectos da língua escrita, mas também aspectos comportamentais, valores, crenças, sistemas simbólicos e tecnológicos, a fim de ativar as identidades sociais dos indivíduos nas práticas sociais nas quais se inserem, assim, propõe grafia do termo com "D maiúsculo".
} 
No entanto, muitas vezes o aluno que ingressa na universidade rompe inicialmente com alguns requisitos de forma, conteúdo e estilo que são próprios desse domínio na constituição do discurso acadêmico e que, por sua vez, caracterizaria os gêneros discursivos dessa esfera. Entende-se que essa ruptura não se dá de forma intencional, mas pelo desconhecimento de quais são esses requisitos, já que, ao longo de sua trajetória escolar, o aluno foi submetido ao que Street (1984) chamou de modelo autônomo de letramento, como dito, caracterizado pelo ato de ler como mera atividade de decodificação, sem considerar as práticas sociais, balizadoras do uso da língua.

Considerando que há divergência entre os diversos letramentos, chamamos atenção à forma com que alunos universitários se engajam ao discurso acadêmico; quais sentidos atribuem às práticas escritas desse domínio, bem como quais conflitos têm sido estabelecidos entre professores e alunos, quando não há correspondência entre o letramento do estudante e o letramento que lhe é exigido por parte dos professores e da instituição. Ou seja, ao entrar na universidade, a esse estudante é solicitado produzir gêneros discursivos que nunca lhe foram ensinados, mas que, de algum modo, lhe são cobrados.

É consenso que os textos são situados e reconhecidos por disciplinas conforme suas especificidades, ou seja, as várias esferas discursivas possuem as suas próprias normas e convenções para produzir conhecimento, além disso, os textos variam linguisticamente em função da sua finalidade e contexto de produção.

Segundo Herdenson e Hirst (2007), quando se fala em letramento acadêmico (textos e atividades especializadas), é importante se pensar em criar condições para abordagens situadas da leitura e da escrita para o desenvolvimento de repertórios flexíveis de letramento. Dessa forma, os estudantes podem transformar e adaptar-se às condições em constante mudança sem deixar de valorizar as suas próprias identidades. Seguindo a mesma direção, Gee (1999) aponta que o sentido dado ao texto é regulado pelo contexto em que está inserido.

Nessa acepção, os estudos do letramento defendem, no contexto da universidade, que o professor promova eventos de letramento - como a própria aula, participação em eventos acadêmicos/científicos, visitas técnicas - que favoreçam práticas de textos acadêmicos inseridos às perspectivas de estudo e de formação profissional do aluno, de modo a fazer com que essas práticas sejam percebidas como resultantes de eventos situados e contextualizados e, assim, fazer com que o texto tenha e faça sentido à vida do aluno.

Ao contemplar práticas textuais em contextos variados, Street (2006) procura demonstrar a variedade e a complexidade dos letramentos, haja vista as relações ideologicamente implicadas nesses diferentes contextos. Dessa forma, fazer com que o estudante universitário sinta-se e perceba-se como tal implica em fazer com que sua leitura e sua produção textual tenham um endereçamento concreto, capaz de realizar ações interlocutoras socialmente constituídas e representativas das posições discursivas historicamente construídas.

Guedes-Pinto (2010), na trilha desses autores, defende a visão dialógica dos letramentos, pois considera as atividades de leitura e escrita em relação ao outro. Para ela, os estudos do letramento tomam a língua como prática social, cujos usos estão relacionados ao contexto imediato, com destaque para aspectos sociais das práticas de letramento e correlação das forças simbólicas em jogo.

\section{OS PROCESSOS INTERACIONAIS, A DIALOGICIDADE E SUAS IMPLICAÇÕES NA LEITURA E NA PRODUÇÃO TEXTUAL NA ESFERA ACADÊMICA}

Considerando que as interações humanas se dão tendo a linguagem como instrumento de mediação, conforme proposição de Vigotski (1984), e que os usos da linguagem se efetivam por meio dos gêneros do discurso, conforme propõe o Círculo de Bakhtin, chamamos a atenção para a importância do estudo dos gêneros discursivos na esfera acadêmica tanto no que diz respeito ao reconhecimento dos gêneros que circulam nesse locus social, quanto seus usos, principalmente, os decorrentes de habilidades que emergem de práticas de leitura e da produção textual, uma vez que os gêneros tomados como unidades textuais/discursivas regulam, organizam e se constituem na interação humana. 
Para isso, faz-se uso da noção de esfera de atividade ou de circulação de discursos como domínio de produção discursiva ou atividade humana em que os gêneros discursivos circulam (BAKHTIN, 1997 [1979]) - familiar, profissional, escolar, acadêmica, jornalística, religiosa, artística, publicitária etc. - em diferentes posições sociais, em que os sujeitos atuam nos diferentes lugares interlocutivos. Esferas essas que organizam o cotidiano a partir da interpenetração de atividade e circulação de discursos na vida das pessoas, (ROJO, 2009).

Conforme Bakhtin (1997 [1979]), o uso da língua está relacionado a essas diversas esferas da atividade humana, por isso o fato de o caráter e as formas desse uso ser tão variado como as próprias esferas. Para o autor, o funcionamento da língua se dá em formas de enunciados (orais e escritos [e podemos acrescentar, de outras formas semióticas]) concretos e singulares, que emanam dos participantes nos processos de interação. Esses enunciados refletem as condições específicas e o objeto de cada uma das esferas comunicativas, não somente por seu conteúdo (temático) e por seu estilo verbal, ou seja, pela seleção dos recursos lexicais, fraseológicos e gramaticais da língua, mas também, sobretudo, por sua composição. Bakhtin aponta que esses três elementos conteúdo temático, estilo e construção composicional - estão vinculados indissoluvelmente na totalidade do enunciado e são determinados de modo semelhante pela especificidade de uma dada esfera de comunicação. "Qualquer enunciado considerado isoladamente é, claro, individual, mas cada esfera de utilização da língua elabora seus tipos relativamente estáveis de enunciados, sendo isso que denominamos gêneros do discurso." (BAKHTIN, 1997 [1979], p. 279).

A relação que Bakhtin aponta entre conteúdo temático, estilo e composição e seus vínculos na totalidade do enunciado é fundamental para compreendermos que é através da situação de interação social que se constituem e funcionam os gêneros. O tema da enunciação é concreto, como o instante histórico ao qual ela pertence. Somente a enunciação, em toda sua amplitude concreta, como fenômeno histórico, possui um tema.

Importante marcar também que cada situação de interação irá produzir aquilo que Bakhtin compreende como reação-resposta ativa responsiva. As múltiplas possibilidades de respostas estão ligadas à multiplicidade de significação do enunciado. Para Bakhtin [Volochínov] (2002 [1929]), a multiplicidade/plurivalência das significações é o índice que faz de uma palavra uma palavra.

A noção de recepção/compreensão ativa proposta pelo Círculo ilustra o movimento dialógico da enunciação, a qual constitui o território comum do locutor e do interlocutor. O locutor enuncia em função da existência de um interlocutor, requerendo deste uma atitude responsiva, com antecipação do que o outro vai dizer, isto é, experimentando ou projetando o lugar de seu ouvinte.

Assim, na visão de Bakhtin [Volochínov] (2002 [1929], p. 123):

A verdadeira substância da língua não é constituída por um sistema abstrato de formas linguísticas nem pela enunciação monológica isolada, nem pelo ato psicofisiológico de sua produção, mas pelo fenômeno social da interação verbal, realizada através da enunciação ou das enunciações. A interação verbal constitui assim a realidade fundamental da língua (grifos do autor).

Bakhtin considera o dialogismo, dentre outras questões, como as relações que ocorrem entre interlocutores, em uma ação histórica compartilhada socialmente, isto é, que se realiza em um tempo e local específicos, mas sempre mutável, devido às variações do contexto. Segundo Bakhtin, o dialogismo é constitutivo da linguagem, pois mesmo entre produções monológicas (a externalização monológica) observamos sempre uma relação dialógica; portanto, todo gênero do discurso é dialógico.

Com isso, os gêneros discursivos emergem, organizam, regulam e orientam as práticas discursivas em lugares determinados socialmente. A universidade é um desses lugares, sendo que esse estrato social goza de muito prestígio. Assim, os processos comunicativos nessa esfera exigem dos estudantes domínio dos gêneros postos em circulação nesse ambiente, visto que os enunciados que sobressaem na instância acadêmica ganham destaque por estarem relacionados à construção e disseminação do conhecimento e envolvem, sempre, uma relação de saber e poder entre aqueles que se constroem identitariamente nesse espaço. 
Nesse sentido, dadas as práticas sociais de interação nessa instância de letramento, faz-se mister ao estudante universitário fazer uso dos gêneros discursos visando sua inclusão nesse espaço. Para isso, é importante reconhecer e estar apto à prática de produção de textos escritos de vários gêneros, como fichamento, diário de leitura, resumo, relatório, memorial, resenha, artigo acadêmico, entre outros; e orais, como, apresentação de seminários, debates, palestras etc.

Nessa perspectiva, compreender a leitura e a produção textual a partir das concepções de letramento e dos gêneros discursivos implica pensarmos essas atividades como ações discursivas nas diversas esferas de atividade humana, ou seja, relacionadas diretamente entre a vida e os sujeitos postos em relações interpessoais. Dadas as possibilidades dessas atividades, convém tratarmos os termos no plural, assim, leituras e produções textuais ganham a devida abrangência de suas funções diversas considerando-se que seus usos estão relacionados a finalidades específicas em contextos de uso situados (BARTON; HAMILTON; IVANIC, 2000) socialmente.

A partir disso, pensar a leitura pode nos levar primeiramente a duas funções: a primeira, cristalizada como atividade erudita em que, aquilo que se lê, pouco tem a ver com vida do leitor, da qual se destacam as obras literárias (leitura de fruição). E a segunda, como uma prática cotidiana (e necessária) para execução de atividades humanas. Assim, é preciso se estar atento para aquilo que se lê, onde, como e quando se lê e, sobretudo, por que se lê, mediante diferentes finalidades.

Na questão das leituras fomentadas na universidade, é importante que o professor considere as histórias de leituras dos ingressantes a essa esfera social. Os alunos chegam à universidade com visões de mundo distintas e isso reflete também no modo como esses sujeitos foram construindo seus repertórios de leituras, bem como foram também constituídos por essas leituras, na maioria das vezes, distintas daquelas que têm prestígio na universidade e que constituem a rede de conhecimento prévio desses alunos.

Zavala (2010) aponta uma heterogeneidade entre os alunos na universidade em virtude da salutar massificação do ensino superior. Justifica afirmando que, no passado, os alunos provinham de uma elite cuja formação caracterizava-se pela homogeneidade, e que contemporaneamente estão, no mesmo lugar, estudantes com formações distintas, ou seja, com diferentes maneiras de pensar, atuar, valorizar e falar, o que, consequentemente, gera conflito. Roland Barthes (1988) radicaliza essa ideia em A morte do autor em prol do nascimento do leitor de um texto. Para Barthes, um texto é feito de escritas múltiplas, oriundas de várias culturas e que entram umas com as outras em diálogo, em paródia, em contestação. No entanto, entende que há um lugar onde essa multiplicidade se reúne, e esse lugar é o leitor. Já para Geraldi (1997), o trabalho de leitura se dá num processo dialógico entre leitor e autor, ou seja, na interação entre ambos, mas descarta a sobreposição da voz do leitor à voz autor.

Assim, sem desconsiderar o efeito da autoria, dizemos que a leitura, em textos de diferentes gêneros discursivos, implica construção de sentidos, o que requer participação ativa do leitor, que coaduna o seu conhecimento prévio ao conteúdo veiculado pelo autor no processo de interpretação/compreensão de textos. Consequentemente, todo texto terá uma relação com um auditório específico, possibilitando uma leitura, também específica. Nos termos de Orlandi (2006 [1988]), toda leitura tem sua história. A autora argumenta que, para um mesmo texto, leituras possíveis em certas épocas não foram em outras, e leituras que não são possíveis hoje poderão ser no futuro. Isto pode ser observado em todos nós, uma vez que lemos diferentemente um mesmo texto em épocas e condições diferentes. É por isso também que se fala em efeitos de sentido produzidos pelo texto.

Mesmo pensando na construção de sentido(s) da leitura, uma observação importante encontra-se em Baltar, Cerutti-Rizzatti, Zandomenego (2011): os textos podem ser lidos de modo particular por diferentes leitores em diferentes momentos históricos, no entanto, isso não autoriza a cada leitor conferir ao texto uma interpretação tão particularizada a ponto de tangenciar ou deformar o que está escrito no texto, ou evadir sobre tal conteúdo. Mesmo considerando-se a diversidade de repertórios de mundo de cada leitor, os textos são produzidos a partir de um projeto, plano de conteúdo, do qual sentidos precisam ser depreendidos, caso contrário cada leitor poderia entender o texto de modo tão particular que não encontraria convergência na leitura de outros sujeitos. Nessa direção, podemos dizer que há sentido(s) possível(is) para o texto, mas não se trata de qualquer sentido. Assim, para um mesmo texto, leitores diversos precisam minimamente evidenciar pontos comuns da leitura partilhada. O que se observa é que há gêneros discursivos que permitem maior variedade de leitura, como os poemas (requer mais subjetividade), e outros que apresentam um espectro menor, a exemplo dos técnico-científicos (requer mais objetividade). 
A interação entre leitor e autor a partir dos gêneros discursivos empreende um diálogo que provoca no leitor algum modo de transformação, uma vez que, para Bakhtin [Volochínov] (2002 [1929]), o sujeito se constitui na alteridade; e ainda, nos dizeres de Vigotski (1984), internalizamos nossas representações de mundo por meio das relações intersubjetivas, assim, a partir da leitura, somos levados a ampliar nosso horizonte apreciativo.

Desse modo, entende-se que ler com proficiência gêneros textuais/discursivos da esfera acadêmica contribui significativamente para a apropriação de conteúdos temáticos, de recursos de estilo e de informações sobre configuração composicional desses gêneros; apropriação essa que poderá contribuir substancialmente na produção de textos congêneres. Nesse sentido, também, apontamos a importância das relações dialógicas no processo de apropriação dos gêneros acadêmicos. Os gêneros em si encontram-se relativamente estabilizados, nos termos de Bakhtin, no entanto, o aluno que chega à Universidade pode não reconhecer de imediato os elementos constitutivos, particulares e diferenciais desses gêneros.

No tangente à escrita, um texto menos previsível precisa veicular conteúdo mais informativo de modo a promover sua recepção de forma mais interessante e envolvente. Para isso, é essencial um intenso processo de leitura de textos em gêneros discursivos diversos que versem sobre o tema a ser abordado. Caso contrário, o ato de produção textual poderá ficar comprometido. Assim, quanto mais fomentada a leitura de textos nos gêneros discursivos na esfera acadêmica, mais efetivamente os alunos universitários tenderão a produzir, com precisão, clareza e objetividade, esses textos e, sobretudo, observando a adequação interacional, a apropriação àquela esfera da atividade humana e o enriquecimento nas relações intersubjetivas oriundas daquele gênero.

Outro ponto de extrema relevância no tangente às relações entre leitura e produção textual é a importância da refacção do texto, visto que raramente a primeira versão do texto corresponderá à versão final. Há quem diga que não existe texto terminado, e sim textos "abandonados", pois, sempre que se volta ao texto, nota-se algum ponto a ser repensado, reelaborado e, portanto, reescrito, haja vista que, no retorno ao texto, já se está afetado por outras leituras. Disso, afirma-se que tão importante quanto escrever é voltar ao texto (re-elaborá-lo), um ato essencialmente dialógico, um diálogo intersubjetivo, pois, nesse ato, aquele que escreve se vê diante da exterioridade de seu modo de organizar o dizer; um processo auto-reflexivo de (re)conhecimento.

A atividade de reescrever o texto implica um trabalho tão ou mais minucioso quanto o dispensado à primeira versão. É preciso despender um monitoramento em que a leitura do próprio texto é de fundamental importância e requer, tanto quanto possível, distanciamento temporal para uma leitura avaliativa. Logicamente, essa atividade avaliativa, de modo a propiciar a refacção do texto, pode ser feita por um terceiro, e, na universidade, esse é um dos papéis do professor, mas não é exclusivo dele, essa tarefa é, antes de tudo, daquele que escreve, que poderá, também, contar com colaboração de colegas do universo acadêmico.

Cabe, ainda, assinalar a importância de se discutir produção escrita e práticas de leitura, emergentes do contexto da universidade relacionadas ao contexto de sua emergência, em que vozes se sobrepõem e se opõem em processos de formulação e circulação de conhecimento. Nesse sentido, faz-se importante salientar que o dialogismo não deve ser confundido com a polifonia (BAKHTIN, 2008 [1963]), porque aquele é o princípio dialógico constitutivo da linguagem e esta se caracteriza por vozes confluentes veladas ou desveladas no discurso ${ }^{2}$.

Na esteira bakhtiniana, Authier-Revuz (1990) aponta a necessidade de se analisar o princípio da heterogeneidade; a ideia de que a linguagem é heterogênea, isto é, de que o discurso é construído a partir do discurso do outro, que é o “já dito" sobre o qual qualquer discurso se constrói, ou seja, numa relação de alteridade. A autora distingue duas formas de heterogeneidade: a constitutiva e a mostrada. A primeira é aquela que não se mostra no fio do discurso. A segunda é a inscrição do outro na sequência do discurso, alterando sua aparente unicidade.

A heterogeneidade mostrada pode ser ainda marcada e não marcada. Quando for marcada, é da ordem da enunciação, visível na materialidade linguística, como o discurso direto e as aspas, entre outras ocorrências. Se for não marcada, é da ordem do discurso, em que o outro é dado a conhecer sem uma marca unívoca, como o discurso indireto livre, a ironia, as metáforas, os jogos de palavra

${ }^{2}$ Neste trabalho, não discutiremos de forma extensiva a questão da polifonia. Recomendamos a discussão em Tezza (2006) sobre o assunto. 
etc. Já a heterogeneidade constitutiva não revela o outro e é concebida no nível do interdiscurso e do inconsciente. Para elaborar tal conceito, a autora articulou o dialogismo de Bakhtin com o seu de heterogeneidade constitutiva por meio de uma abordagem psicanalítica.

Enquanto o dialogismo se refere às conversações que estruturam uma dada linguagem, a polifonia tem como principal propriedade a diversidade de vozes controversas no interior de um texto.

Além da questão acerca da polifonia e do dialogismo, faz-se mister atentar-se à proposta de Bakhtin (1997 [1979]) em relação à existência de dois grandes grupos de gêneros discursivos: os gêneros primários e os gêneros secundários. Os primários são aqueles que se constituíram na comunicação verbal cotidiana (os tipos de diálogo oral, como a linguagem das reuniões sociais, dos círculos, linguagem familiar, cotidiana, o bilhete, a carta familiar...). Os gêneros secundários são os que aparecem em circunstâncias de uma comunicação cultural, mais complexa e relativamente mais desenvolvida, principalmente escrita: os gêneros das esferas artística, científica, sociopolítica etc.

Bakhtin (1997 [1979]) destaca a importância dessa diferenciação (gêneros primários e secundários), pois a inter-relação entre os gêneros primários e secundários de um lado, o processo histórico de formação dos gêneros de outro (BAKHTIN, 2008 [1963]), é o que esclarece a natureza do enunciado; e, além disso, o difícil problema da correlação entre língua, ideologias e visões de mundo.

$\mathrm{O}$ autor fala que não podemos ignorar a natureza do enunciado, tampouco as particularidades dos gêneros, que assinalam a variedade do discurso em qualquer área do estudo linguístico, ou seja, não podemos desvirtuar a historicidade do estudo para não enfraquecer o vínculo existente entre a língua e a vida. "A língua penetra na vida através dos enunciados concretos que a realizam, e é também através dos enunciados concretos que a vida penetra na língua” (BAKHTIN, 1997 [1979], p. 282).

Os gêneros discursivos emergem, organizam, regulam e orientam as práticas discursivas em lugares determinados socialmente. A universidade é um desses lugares. Assim, os processos comunicativos nessa esfera exigem dos estudantes domínio dos gêneros postos em circulação nesse ambiente, visto que os enunciados que sobressaem na instância acadêmica ganham destaque por estarem relacionados à construção e disseminação do conhecimento, e envolvem sempre uma relação de saber e poder entre aqueles que se constroem identitariamente nesse espaço. Nesse sentido, uma série de vozes pode ser convocada na produção escrita acadêmica a fim de assegurar, garantir, respaldar um caráter de credibilidade ao texto - o que pode ser marcada pela dialogia. No entanto, não basta a sobreposição de vozes, é necessário também despertar no estudante universitário o caráter crítico ao ponto de produzir textos polifônicos que marquem pontos de vistas diferentes entre os interlocutores, ou seja, com voz e postura pessoal acerca do tema em pauta, contrapondo-se em defesa de seu posicionamento.

\section{ANÁLISE DA PRODUÇÃO TEXTUAL}

Como sinalizamos na introdução, propõe-se nesta seção analisar uma produção textual decorrente da última atividade avaliativa desenvolvida por um estudante no final do primeiro semestre de seu ingresso à Universidade. Essa atividade foi proposta como parte da avaliação final destinada aos alunos que, no cômputo de sua média final, não atingiram o percentual suficiente para a aprovação na disciplina de Leitura e Produção Textual Acadêmica.

Cabe anotar que, no decorrer do semestre, as atividades de produção textual pautadas pelos gêneros discursivos acadêmicos foram desenvolvidas a partir de aulas expositivas e dialogadas, tendo como foco o estudo de textos técnico-científicos relevantes para o desempenho das atividades acadêmicas, sobretudo aqueles requeridos nas primeiras fases do ensino superior. Nessa direção, buscou-se desenvolver habilidades que fizessem com que o estudante pudesse reconhecer e distinguir diferentes gêneros 
discursivos, em suas particularidades constitutivo-funcionais. Para tanto, após o estudo do funcionamento de cada gênero, os acadêmicos foram solicitados à produção textual mediante leituras prévias de textos-fonte ${ }^{3}$.

Após a avaliação, os textos eram devolvidos aos estudantes com anotações adjuntas e/ou após o texto. Além das anotações por escrito, era aberto um espaço para que o aluno pudesse, individualmente, questionar as anotações feitas em seu texto. Ao aluno cujo texto era considerado não condizente à expectativa do projeto textual/discursivo ao gênero proposto, era dada a possibilidade de reescrita, sendo esse texto submetido à nova avaliação. Salientamos, ainda, que ao estudante cujo texto passa-se a analisar, em todas as demais produções escritas, foi solicitada a rescrita de seu texto.

Especificamente em relação a essa atividade avaliativa, o texto sob análise constitui-se de uma das três proposições da avaliação, em que objetivo era, a partir da leitura do texto-fonte, elaborar uma resenha.

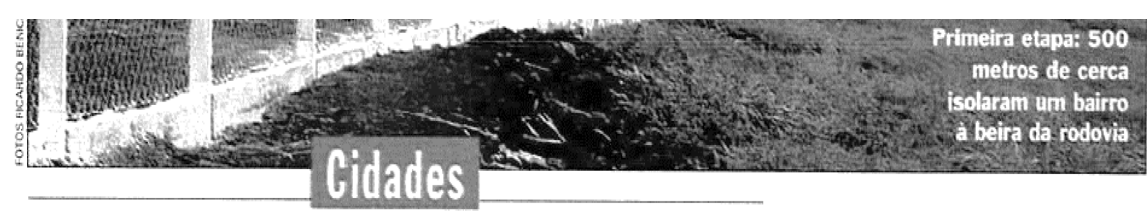

\section{Atrás dos muros}

\section{Para prevenir o crime, cidadezinha está sendo inteiramente cercada por alambrados}

racemápolis é uma pacata cidade de

15000 habitantes, a 160 quilômetros de São Paulo, que se gaba de contar nos dedos de uma mão o número de presos que cumprem pena: são apenas três. A violência é coisa tĭo rara lá que nem che ga a dar trabalho para os dezesseis homens do efetivo da Polícia Militar. Em todo este ano, foram registrados apenas sete roubos. Ainda assim. Iracemápolis dejxou-se contaminar pelo mesmo pavor que aflige as metrópoles e tomou uma provi- habitacional, num percurso de quase 9 quilômetros. "Quero transformar a cidade num grande condomínio fechado", diz Consenza. "Só assim será possível manter a qualidade de vida que temos aqui e evitar futuros problemas de segurança." Quando a obra, orçada em 300000 reais, estiver concluída, no início do próximo ano. ninguém entrará ou sairá despercebido de Iracemápolis. As entradas do município receberũo portais com guaritas de segurança monitoradas por câma- ras de vídeo 24 horas por dia, ligadas a uma central da Polícia Militar. Por enquanto. a cerca ocupa um trecho de 500 metros e divide um bairro de classe média de uma movimentada rodovia, a SP 151. Foi exatamente ali que aconteceu o último e mais violento roubo registrado no município, há dois meses. $\mathrm{O}$ aposentado José da Silva saía de casa para uma caminhada quando foi surpreendido por dois assaltantes armados que levaram sua caminhonete zero-quilômetro e o fizeram refém por uma hora sob a mira de um revólver. Hoje, a cerca passa bem em frente a sua casa. "Estamos bem mais protegidos agora", diz ele.

A idéia de viver em condomínio fechado está sendo levada a sério pelos moradores. Eles não dāo a mínima importância ao fato de Iracemápolis mais parecer uma cidade medieval murada, uma ilha separada

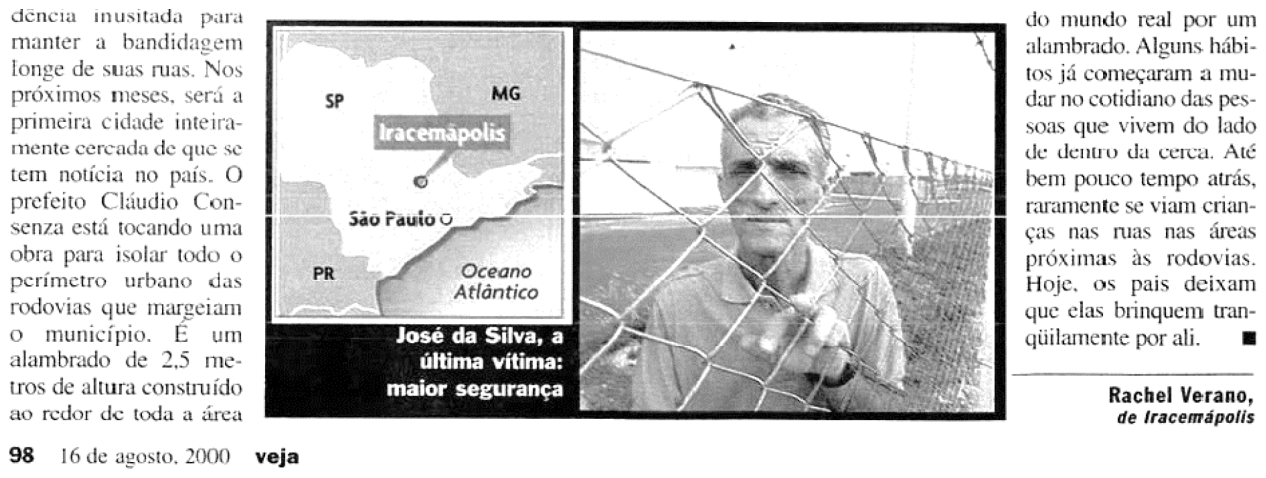

Imagem 1: Reportagem de Veja (texto-fonte)

Fonte: Verano (2000, p. 98)

\footnotetext{
${ }^{3}$ Estamos nomeando texto-fonte aquele do qual as ideias e/ou informações são obtidas. Em particular, a produção de fichamentos, resumos e resenhas mantém, sobremaneira, uma relação de intertextualidade com um texto primeiro.
} 
Quadro 1: Primeira produção escrita

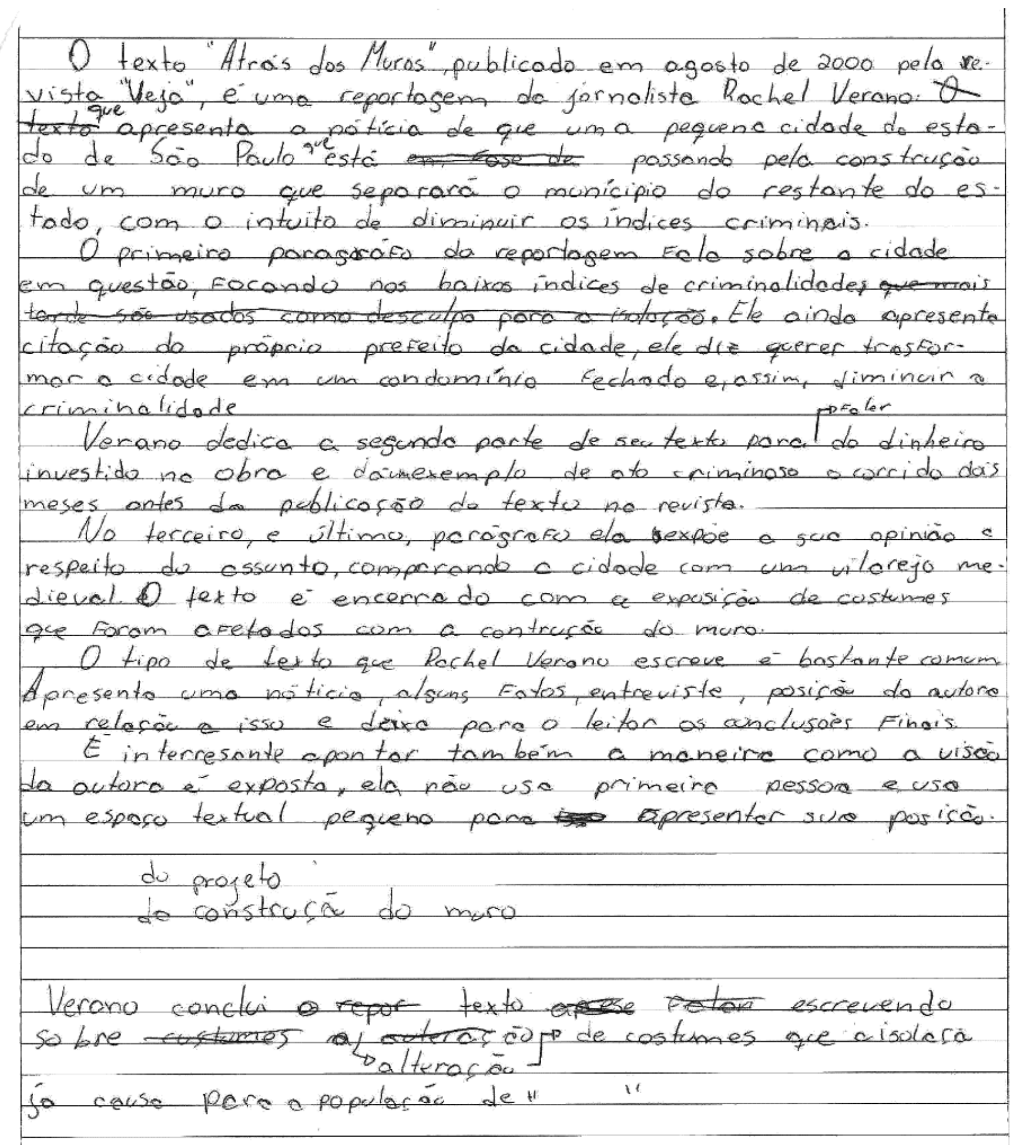

Fonte: Arquivo dos autores

Mesmo tratando-se de uma avaliação final (Exame Final de Leitura e Produção Textual Acadêmica), à medida que os alunos entregavam a prova, optou-se por fazer a avaliação prévia dessa parte do exame, especificamente, uma vez que era a questão com maior peso para a atribuição de nota. Após a leitura, cada aluno recebia um feedback de seu texto oralmente; as anotações no texto eram feitas pelo próprio aluno, caso desejasse. Em seguida, o aluno podia reescrever seu texto, se assim quisesse.

Quadro 2: Segunda produção (reescrita)

0 texto "Atras dos Muras", publicado em agosto de 2000 pela revista "Veja", é umo reportogem da jornalisto Rochel Verano que aptresenta a noticia da construcoo de um muro oque pretende se parar o municipio de Iracemápolis do restante de Sano Pouloe a posicăo de autora quanto do rato inusitado.

0 primeiro paragráfo da reportagem falo da cidade de Iracemápolis e seus baixos indices criminais. Ele apresenta o Fato da construcēon do muro cercondo todo o perímetro urbono e citacáo do prefeito da cidode que, segundo verano, diz querer transfor mor a cidade em um codominio fechodo e, assim, diminuir a criminolidede no municipio

Verano dedica a segundo do seu texto para colar do dinheiro investido na obre e da um exemplo decrime violento ocorrido na cidode dois meses antes da publicocio do texto na revisto

No terceiro, e ultimo paragrafo elo expóe sua opiniá a respeito do assunto, camporando so ridade com un vitarejo medie vol. Verano conclui o texto escrevendo sobre a alterasaio de costumes que isolamento io cause a populasáa de Iracemápolis.

O tipo de texto que Rochel Verono escreve represento umc parcela pequena no meio jornolistico, a presentodo a laim do foto a posiç̃o do autora, embara deixe poro o leitor as canclusoés finai E interessonte abordor tombem a moneire como a autoro expöe sua visou. Elo nà usa primeirn pessa e ocupe um espaco textuel pequeno dondo a impressa de que tambeim campoe o tex to

Fonte: Arquivo dos autores 
(1) Observamos que as rasuras existentes no primeiro texto e ausentes no segundo, são marcas do processo de reescrita do próprio aluno.

(2) A pressão do corpo sobre o instrumento de escrita (caneta) aponta para o traço da letra mais preciso, marcado de forma mais impositiva, no segundo texto em relação ao primeiro, o que pode nos levar à conjectura de maior segurança quando frente ao processo de reescrita, tendo em vista o processo dialógico a que se submeteu após a primeira versão do texto.

(3) As rasuras (riscos, traços, escritas encaixadas, escritas sobrepostas...) inferem o excesso do dizer, as sobras da linguagem, aquilo que precisa ser administrado de modo a tornar possível a produção do projeto de dizer e a construção de um efeito de fecho ao texto.

(4) A marca da assinatura ao segundo texto também pode corroborar a entrada subjetiva ao texto, não só como uma marca de um sujeito empírico que subscreve à sua escrita, mas como evidência do sujeito que se atenta para a necessidade de se inscrever no texto, sobretudo, por se tratar, especificamente, do gênero resenha.

Quadro 3: Comparação do primeiro parágrafo nos dois textos

\section{Primeiro parágrafo - primeira produção}

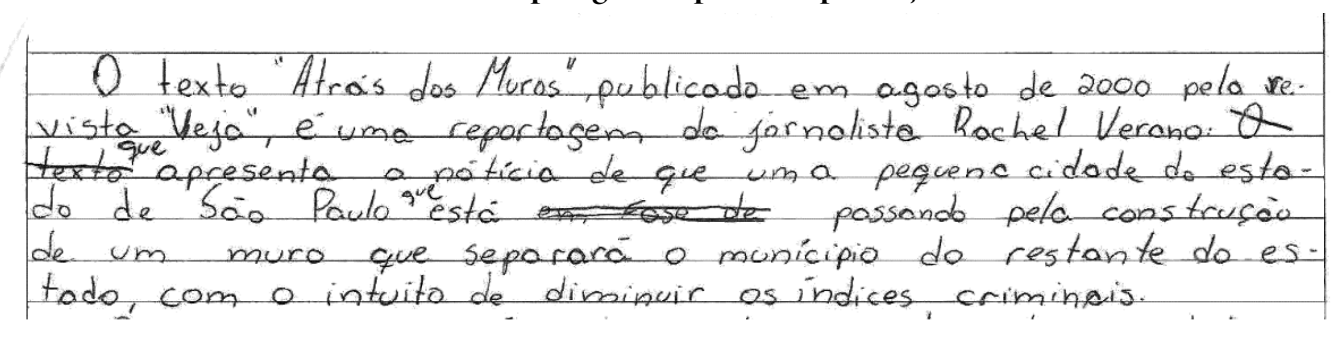

Primeiro parágrafo - segunda produção

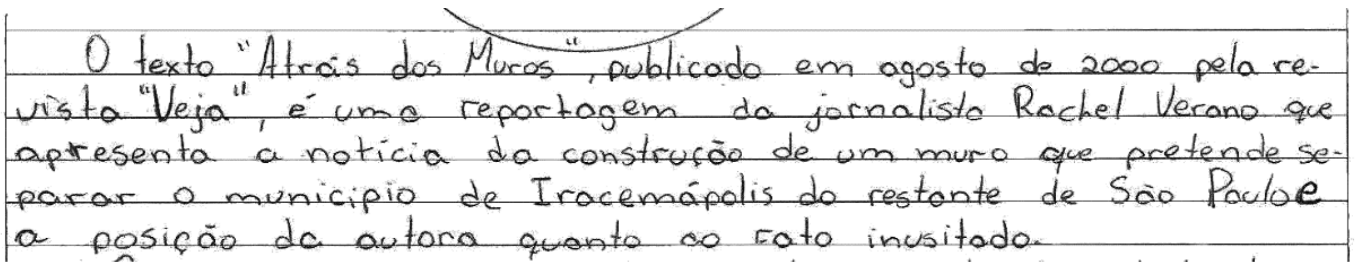

Fonte: Arquivo dos autores

(5) Mesmo tendo como ponto de partida boa parte da formulação no primeiro parágrafo, do texto (1) no (2), o segundo texto altera significativamente a forma de referenciar o assunto-tema da matéria resenhada (separando as informações principais das secundárias; ação intrínseca ao processo de resumir para resenhar). Além disso, atenta para um ponto importante na caracterização da resenha, que consiste em marcar a diferença entre a avaliação do texto daquele que resenha em relação à avaliação posta no próprio texto resenhado:

Quadro 4: Excertos comparativos entre a primeira escrita e a reescrita

Texto 1

apresenta a notícia de uma pequena cidade do estado de São Paulo que está passando pela construção de um muro que separará o município do restante do estado
Texto 2 apresenta a notícia da construção de um muro que pretende separar o município de Iracemápolis do restante de São Paulo e a posição da autora quanto ao fato inusitado 


\section{Segundo parágrafo - primeira produção}

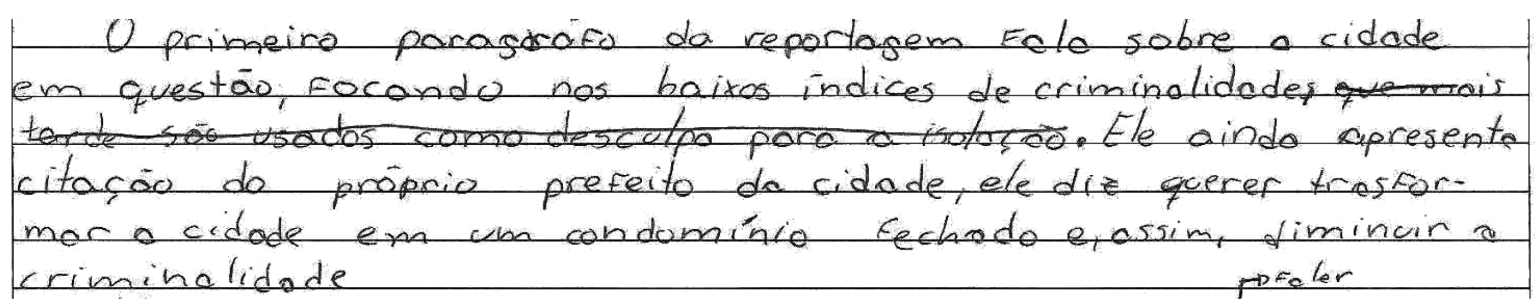

\section{Segundo parágrafo - segunda produção}

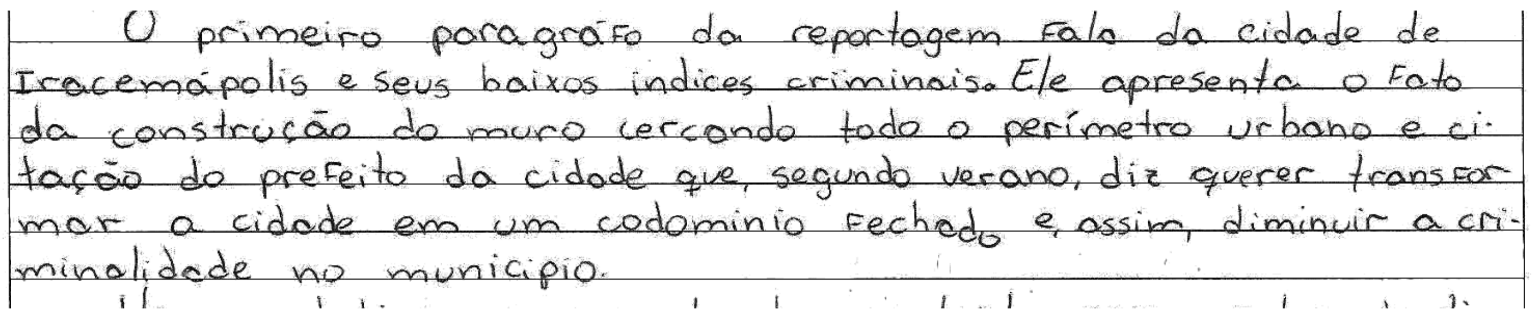

Fonte: Arquivo dos autores

(6) O segundo parágrafo do texto (2) também mantém a ideia inicial parafrástica ao texto (1), com a diferença de registrar o nome da cidade em questão. No entanto, a mudança mais significativa é marcada pelo registro da sobreposição de vozes:

Quadro 6: Excertos comparativos entre a primeira escrita e a reescrita

\begin{tabular}{c|c} 
Texto 1 & Texto 2 \\
\hline $\begin{array}{c}\text { Ele ainda apresenta citação do próprio prefeito da cidade, ele diz } \\
\text { querer transformar a cidade em condomínio fechado }\end{array}$ & $\begin{array}{c}\text { Ele apresenta [...] e citação do prefeito da cidade que, segundo Verano, diz } \\
\text { querer transformar a cidade em condomínio fechado }\end{array}$
\end{tabular}

Fonte: Elaboração dos autores

A essa sobreposição de vozes pode-se ainda dizer que uma outra voz se soma, explicitando o que Authier-Revuz (1990) chama de heterogeneidade mostrada e marcada no discurso (discurso indireto); a voz daquele que se põe a resenhar. O que se poderia chamar de uma marca duplamente dialógica. Indo além, o modo como essa sobreposição de vozes é explicitado pode servir de índice para a presença da polifonia no texto resenhado, nos termos de Bakhtin (1997 [1979]). Nesse caso, a polifonia não se restringe ao dialogismo, mas a posições distintas que marcam cada voz dentro do texto, dirigindo cada discurso presente no texto-resenha. Ao dizer "segundo Verano", o discurso indireto estaria denotando a indicação de uma voz à outra, mas ao acrescentar "diz querer", o texto (2) marca a posição daquele que escreve ao apontar a latência de uma possibilidade de dúvida em relação à referência da voz de um sujeito na voz de outrem. 


\section{Quarto parágrafo - primeira produção}

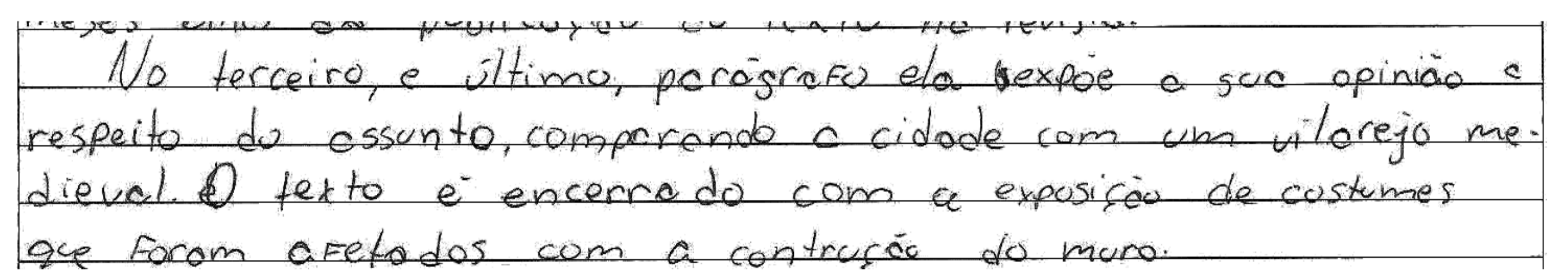

\section{Quarto parágrafo - segunda produção}

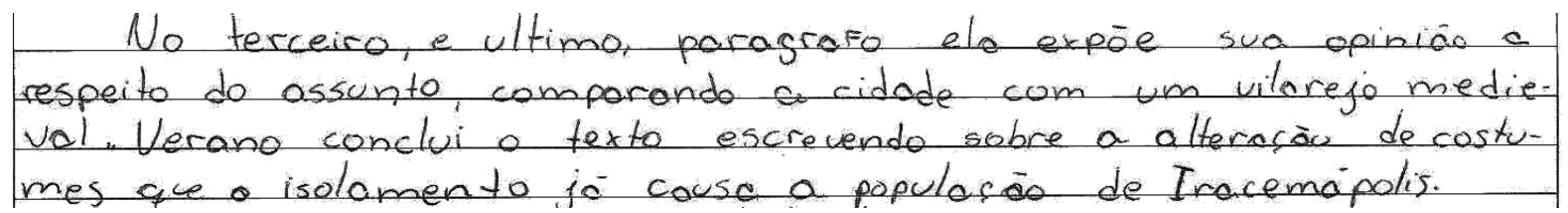

Fonte: Arquivo dos autores

(7) Ao modo da refacção dos outros parágrafos, o texto (2) mantém a estrutura inicial do texto (1) e produz alteração significativa (ao final do parágrafo) ao se inscrever como sujeito dessa escrita na relação com a escrita do outro. Dito de outro modo, a característica que marca o gênero resenha surge justamente na refacção, no ponto em que aquele que se põe e resenhar dialoga com o texto-fonte, mas não restringe-se a reportar as informações contidas naqueles texto.

Quadro 8: Excertos comparativos entre a primeira escrita e a reescrita

Texto 1

\begin{tabular}{c|} 
Texto 1 \\
\hline O texto é encerrado com a exposição de costumes que foram \\
afetados com a construção do muro.
\end{tabular}

Fonte: Elaboração dos autores
Texto 2

Verano conclui o texto escrevendo sobre a alteração de costumes que o

isolamento já causa a população de Iracemápolis.

Ao substituir a construção "o texto é encerrado" por "Verano conclui", a resenha alcança o propósito para além de trazer a informação sintetizada do texto-fonte, uma vez que, novamente, num processo dialógico, aponta para a voz e posição do outro presente na construção de um texto "aparentemente" informativo como é o jornalístico. 


\section{Quinto e sexto (último) parágrafo - primeira produção}

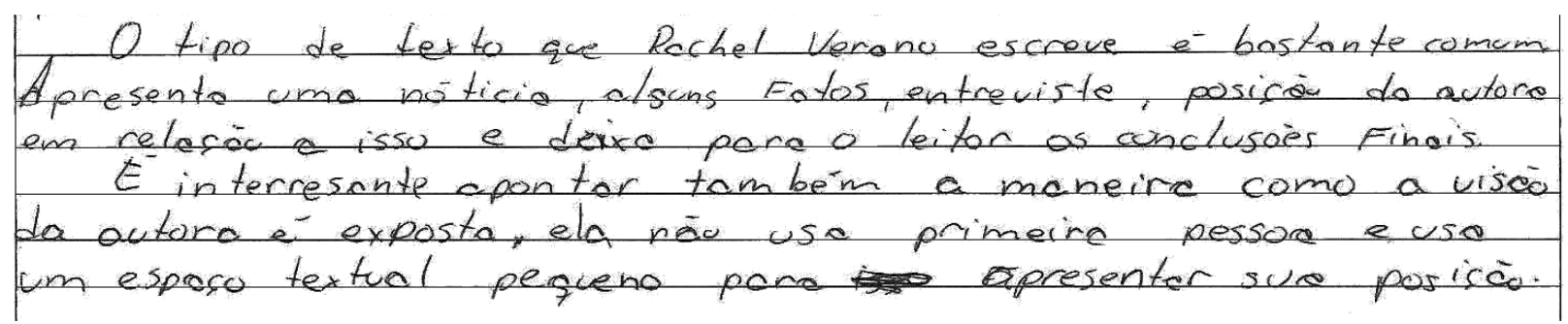

\section{Quinto e sexto (último) parágrafo - segunda produção}

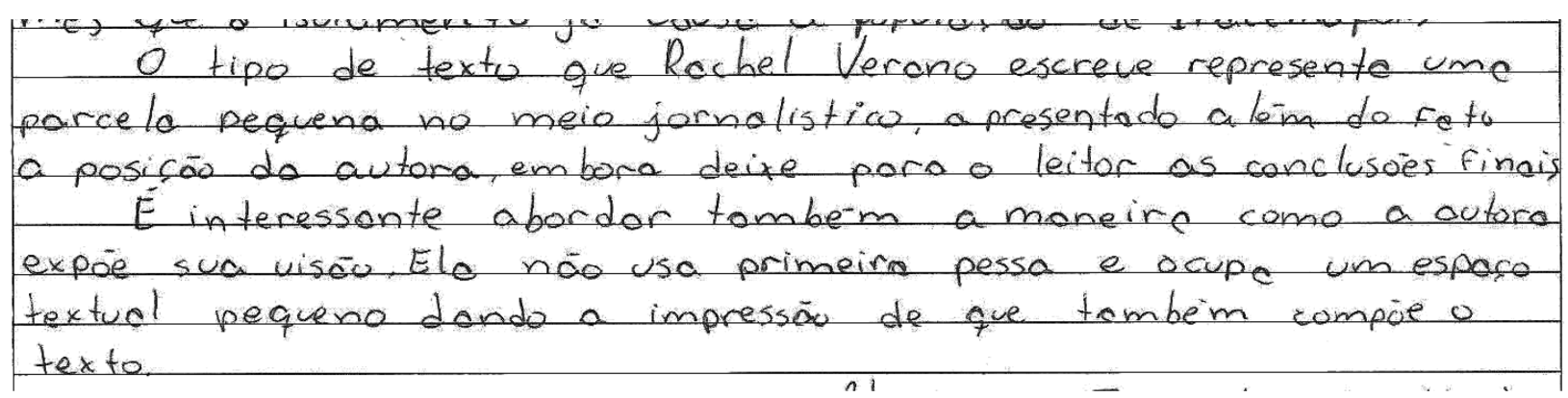

Fonte: Arquivo dos autores

Após a apresentação, nos parágrafos antecedentes, da estrutura do texto resenhado e do modo como a autora marca-se no texto, ora pautada por estratégias de trazer informações de cunho jornalístico, ora por assumir sua posição em relação à matéria veiculada, os dois últimos parágrafos da resenha buscam um efeito de finalização alçada na avaliação do texto-fonte. Ao fazer isso, o aluno novamente intenta assegurar a caracterização do gênero resenha ao explicitar sua percepção geral acerca do modo como a jornalista escreve sua matéria. Vale notar que, apesar de o quarto parágrafo apresentar um posicionamento diferente acerca da avaliação da matéria no texto (1) para o texto (2),

Quadro 10: Excertos comparativos entre a primeira escrita e a reescrita

\begin{tabular}{c|c} 
Texto 1 & Texto 2 \\
\hline O tipo de texto que Rachel Verano escreve é bastante comum & $\begin{array}{r}\text { O tipo de texto que Rachel Verano escreve representa uma parcela pequena } \\
\text { no meio jornalístico }\end{array}$
\end{tabular}

Fonte: Elaboração dos autores

o que pode ser um reflexo do processo dialógico estabelecido com o professor durante o feedback da primeira versão, há a manutenção de uma tentativa de se posicionar em relação ao texto resenhado e garantir que o gênero que está escrevendo é de fato uma resenha, assim, percebe-se um gesto de inscrição desse sujeito em sua escrita. 


\section{EFEITO DE FECHO}

A articulação dos elementos teóricos da Linguística Aplicada, sobretudo aqueles que discutem as práticas de letramento na Universidade, aliados a uma perspectiva discursiva, possibilitaram a análise, aqui proposta, de modo a produzir uma reflexão de como é possível, por meio de uma relação dialógica entre professor e aluno, mobilizar o sujeito-aluno que escreve nessa esfera para que, ao escrever, possa também se inscrever. Além disso, apontou-se, ainda, que essa inscrição pode ser evidenciada por marcas de como o sujeito que escreve produz diálogos, também, com os textos que lê, para, desse modo, corroborar ou contrapor-se às ideias do outro. E, nesse gesto, abre-se a possibilidade de espaço à polifonia, nos termos do Círculo bakhtiniano.

Por fim, alude-se aos autores Rojo (2001), Gatinho (2004) e Almeida (2003). Rojo (2001), optando por um trabalho dialógico com a linguagem e considerando as discussões teóricas do Círculo de Bakhtin, afirma que, por meio dos gêneros discursivos, adotados como objeto de ensino, abrem-se portas para a escola/universidade melhor prosseguir na formação de cidadãos capazes de interagirem criticamente com os discursos alheios e com os próprios discursos. Gatinho (2004) propõe os gêneros como estratégia de ensino e aprendizagem, mas que não se deve engessá-los, assim, não se deve usá-los como modelo de práticas discursivas sem, contudo, evidenciar seu caráter dialógico com outros gêneros e sua dinamicidade. Desse modo, na esfera acadêmica, com o apoio de trabalhos sistemáticos com gêneros discursivos, orientados por professores, abrem-se espaços para que haja o deslocamento do papel de aluno para aluno-sujeito na construção de sentidos nas propostas de leitura e de produção escrita. E para Almeida (2003), abre-se a possibilidade para esses sujeitos de se assumirem agentes sociais no trabalho com a linguagem, participantes num processo dialógico, em que se constituem sujeitos históricos mais reflexivos.

\section{REFERÊNCIAS}

ALMEIDA, P. R. O querer-dizer na (re) constituição. In: ABAURRE, M. B. M.; MAYRINK-SABINSON, M. L. T.; FIAD, R. S. (Org.). Estilo e gênero na aquisição da escrita. Campinas: Komedi, 2003. p. 103-130.

AUTHIER-REVUZ, J. Heterogeneidade enunciativa. Cadernos de estudos linguísticos, Campinas, 1990. p. 25-42.

BAKHTIN, M. M. Questões de literatura e de estética: a teoria do romance. Tradução do russo por Aurora Fornoni Bernardini et al. 4. ed. São Paulo: UNESP; Hucitec, 1998 [1975].

. Estética da Criação Verbal. Tradução do russo por Paulo Bezerra. 4. ed. São Paulo: Martins Fontes, 1997 [1979].

. (VOLOCHÍNOV, V. N.). Marxismo e Filosofia da Linguagem: Problemas fundamentais do método sociológico na ciência da linguagem. Tradução do francês por Michel Lahud e Yara F. Vieira. 12. ed. São Paulo: Hucitec, 2002 [1929].

. Problemas da Poética de Dostoiévski. Tradução do russo, notas e prefácio de Paulo Bezerra. 4. ed. Rio de Janeiro: Forense Universitária, 2008 [1963].

BALTAR, M. A. R.; CERUTTI-RIZZATTI, M. E.; ZANDOMENEGO, D. Leitura e produção textual acadêmica I. Florianópolis: LLV/CCE/UFSC, 2011.

BARTHES, R. O rumor da língua. São Paulo: Brasiliense, 1988.

BARTON, D. Literacy: an Introduction to the ecology of written language. London: Blackwell, 1994.

BARTON, D.; HAMILTON, M. Local literacy: reading and writing in one community. London, New York: Routledge, 1998. 
BARTON, D.; HAMILTON, M.; IVANIC, R. Situated literacies. Reading and writing in context. London, New York: Routledge, 2000. p. 180-196.

GATINHO, J. B. M. A(s) noção(ões) de gênero discursivo subjacente(s) às práticas de sala de aula de língua materna. In: SIGET SIMPÓSIO NACIONAL DE ESTUDO DOS GÊNEROS TEXTUAIS, 2., 2004, União da Vitória. Anais... União da Vitória: FaFI, 2004. 1 CD-ROM.

GEE, J. P. Social linguistics and literacies: ideology in Discourses. 2. ed. London, Philadelphia: The Farmer Press, 1999.

. Reading as situated language: a sociocognitive perspective. Journal of adolescent \& adult literacy, Newark, v. 8, n. 44, p. 714725, 2001.

GERALDI, J. V. Portos de passagem. São Paulo: Martins Fontes, 1997.

GUEDES-PINTO, A. L. Usos de práticas de escrita na formação inicial de professores: interfaces possíveis com os estudos de letramento. In: SERRANI, Silvana (Org.). Letramento, discurso e trabalho docente. Vinhedo: Editora Horizonte, 2010. p. 129 -142.

HAMILTON, M. Sustainable literacies and the ecology of lifelong learning. Working Papers of the Global Colloquium on Supporting Lifelong Learning, Milton Keynes, 2000.

HENDERSON, R.; HIRST, E. Reframing academic literacy: re-examining a short course for "disadvantaged" tertiary students. English teaching: practice and critique, New Zealand, v. 6. n.2, p. 25-38, 2007.

LEA, M.R.; STREET, B. Student Writing in higher education: an academic literacies approach. In: Studies in Higher Education, London, v. 23, n. 2, p. 157-172, jun.1998.

. The academic literacies model: theory and applications. Theory into Practice. Philadelphia, v. 4, n. 45, p. 368-377, 2006.

MEDVIÉDEV, P. N. O método formal nos estudos literários: introdução crítica a uma poética sociológica. Tradução do russo por Ekaterina Américo e Sheila Grillo. São Paulo: Contexto, 2012 [1928].

ORLANDI, E. P. Discurso e texto: formulação e circulação dos sentidos. Campinas: Pontes, 2001.

. Discurso e leitura. 7. ed. São Paulo: Cortez, 2006 [1988].

. Análise do discurso: princípios e procedimentos. 6. ed. Campinas: Pontes, 2007 [1990].

ROJO, R. A teoria dos gêneros em Bakhtin: construindo uma perspectiva enunciativa para o ensino de compreensão e produção de textos na escola. In: BRAIT, B. (Org.). Estudos enunciativos no Brasil: histórias e perspectivas. São Paulo: Pontes; Fapesp, 2001. p. $163-185$.

. Letramentos múltiplos, escola e inclusão social. São Paulo: Parábola, 2009. 
STREET, B. V. Literacy in theory and practice. London: Cambridge University Press, 1984.

Social literacies - critical approaches to literacy in development, ethnography and education. Harow: Pearson, 1995.

. Perspectivas interculturais sobre o letramento. Trad. Marcos Bagno. Filologia linguística do português, São Paulo, n. 8, p. 465-488, 2006.

VERANO, R. Atrás dos muros. Veja, São Paulo, p.98, 16 ago. 2000. Disponível em: <https://www.google.com.br/?gws_rd=ssl\#q=veja+26+agosto+2000>. Acesso em: 03 mar. 2015.

VOLOCHÍNOV, V. N. A construção da enunciação e outros ensaios. Organização, tradução e notas de João W. Geraldi. São Carlos/SP: Pedro \& João Editores, 2013.

VYGOTSKY, L. S. A formação social da mente. São Paulo: Martins Fontes, 1984.

ZAVALA, V. Quem está dizendo isso? Letramento acadêmico, identidade e poder na educação superior. In: VÓVIO, C; SITO, L; GRANDE, P. de. (Org.). Letramentos. Campinas, SP: Mercado das Letras, 2010. p. 71-95. 